Article

\title{
Experimental Research on Grape Cluster Vibration Signals during Transportation and Placing for Harvest and Post-Harvest Handling
}

\author{
Muhammad Faheem ${ }^{1,2}{ }^{\oplus}$, Jizhan Liu ${ }^{1, *}$, Guozheng Chang ${ }^{1}$, Irfan Abbas ${ }^{1}$, Binbin Xie ${ }^{1}$, Zhu Shan ${ }^{1}$ and \\ Kaiyu Yang ${ }^{1}$ \\ 1 Key Laboratory of Modern Agricultural Equipment and Technology, Ministry of Education, \\ Jiangsu University, Zhenjiang 212013, China; engr.faheem@uaf.edu.pk (M.F.); \\ 2111916017@stmail.ujs.edu.cn (G.C.); $5103180336 @ s t m a i l . u j s . e d u . c n(I . A$. \\ 2111816004@stmail.ujs.edu.cn (B.X.); 2112016015@stmail.ujs.edu.cn (Z.S.); \\ 2221916041@stmail.ujs.edu.cn (K.Y.) \\ 2 Department of Farm Machinery and Power, University of Agriculture, Faisalabad 38000, Pakistan \\ * Correspondence: liujizhan@163.com; Tel./Fax: +86-511-88797338
}

check for updates

Citation: Faheem, M.; Liu, J.; Chang, G.; Abbas, I.; Xie, B.; Shan, Z.; Yang, K. Experimental Research on Grape Cluster Vibration Signals during Transportation and Placing for Harvest and Post-Harvest Handling. Agriculture 2021, 11, 902. https:// doi.org/10.3390/agriculture11090902

Academic Editor:

Francesco Marinello

Received: 28 July 2021

Accepted: 14 September 2021

Published: 19 September 2021

Publisher's Note: MDPI stays neutral with regard to jurisdictional claims in published maps and institutional affiliations.

Copyright: (C) 2021 by the authors. Licensee MDPI, Basel, Switzerland. This article is an open access article distributed under the terms and conditions of the Creative Commons Attribution (CC BY) license (https:/ / creativecommons.org/licenses/by/ $4.0 /)$.

\begin{abstract}
Berry dropping or shattering is an important factor during the harvest and post-harvest handling of fresh eating grapes until they reach the supermarkets. There are a lot of methods to measure post-harvest placing damage and the detachment force for single fruits. However, until now, there has been no objective method to observe and analyze the berry dropping mechanism of cluster fruits during robotic post-harvest handling. Therefore, in this paper, the effect of a cluster's vibration on berry drop during vertical transportation and the impact of different packaging materials on fresh grape clusters during robotic placing were analyzed. For this purpose, a lead screw lathe, along with an attached actuator, three grape cluster samples $(0.48,0.50,0.53 \mathrm{~kg})$, three packaging materials (rigid plastic box, corrugated fiberboard box, expandable polystyrene box), four transportation speeds (0.4, $0.6,0.8,1.0 \mathrm{~m} / \mathrm{s})$, and four acceleration excitations $\left(6,8,10,12 \mathrm{~m} / \mathrm{s}^{2}\right)$ that were given in a mechanical system (actuator) were studied. In order to analyze the berry drop mechanism of grape clusters before and after the impact with packaging material, a force sensor and high-speed video camera were used. It was concluded from the vertical transportation test that with the increase in speed and acceleration excitations, the change in hanging force increased positively $\left(R^{2}=0.92\right)$. Additionally, the force after the striking of the grape cluster with packaging materials decreased negatively $\left(R^{2}=0.97\right)$, and the corresponding index of berry deflection increased. It was also observed from the high-speed camera images that rigid plastic boxes caused the maximum deflection of the grape berries, with the highest change in force of $8.6 \mathrm{~N}$ after the impact. Experimental results showed a negative correlation between the hanging force signals and the force after impact of the cluster, with a goodness of fit of $R^{2}=0.95$ at different speeds. Overall, the proposed findings can be used as a reference study for improving robotic post-harvest handling, providing a useful visual and technical understanding of the berry fall susceptibility of cluster fruits, and can be used to develop a post-harvest robotic placing tool for avoiding berry drop damage on both industrial and farm levels.
\end{abstract}

Keywords: grapes; cluster fruits; packaging materials; transportation and placing; excitation; vibration; signals

\section{Introduction}

Grapes occupy an important place in the world; their annual output has reached about 79 million tons [1]. Grape cultivars can be categorized into four main groups for food usage: table grapes, wine grapes, sweet juice grapes, and raisin grapes [2]. Among these, table grapes occupy an important place in global fresh cluster fruit production. Because of their high quality, attractiveness, and numerous nutritional facts [3], more than $65 \%$ of 
grapes produced are consumed as a fresh eating fruit [4]. The yield of fresh eating table grapes is enhanced by the development of the grape industry [5].

Table grapes are not a climacteric fruit, and in the process of harvesting and postharvest operations such as storage, packaging, transportation, and logistics, table grapes undergo serious mechanical loads due to impact, collision, and long-term vibration. These mechanical loads cause the berry falling of clusters. Therefore, it is of great significance to analyze the berry drop mechanism of grape clusters during post-harvest operations to improve the quality and shelf life of grape clusters and reduce the economic loss of the producer. The harvest and post-harvest handling of fresh eating table grapes are in the form of clusters or bunches until they reach the supermarkets. As to manual or robotic handling during the harvesting and post-harvest of fresh grape clusters, the mechanism and phenomenon of damage are totally different from single stem fruits [6]. Usually, grape clusters are clamped and cut from the main rachis. The hanging cluster, after cutting, needs to be transported to a basket or box, then unloading and placed into a basket or bulk bin to complete the on-site transportation. Additionally, for long-distance transportation or post-harvest operations, grape clusters need to be handled several times [7-15]. So the probability of berry drop greatly increases. The loss caused by the berry drop and decay of fruit grain is up to $20 \%$ to $30 \%$. The integrity of fresh cluster fruit and non-destructive evaluation are two major quality criteria of grape clusters [16]. The problem of berry fall seriously affects their shelf life and marketability $[10,17,18]$, which has become a serious problem that has plagued the table grape industry chain for a long time. Additionally, it has become a key obstacle to the development and control of machinery and robotic equipment for grape cluster post-harvest handling. Therefore, basic research on grape cluster vibration signals can help to predict and grasp the berry dropping mechanism during robotic transportation and placing. This study will help suggest an effective means of control that has important scientific significance and commercial value.

Mechanical loads have been known for many years as a major factor causing postharvest losses and damage to many single stem fruits. The dynamic impact of collision is the main cause of single stem fruit damage. Many studies have been carried out on the impact damage of various kinds of single stem fruits all over the world. The most common methods to determine impact loading damage are as follows: (1) drop tests [19-23]; (2) pendulum action, either by attaching a fruit to the pendulum $[24,25]$ or by hitting the fruit with a pendulum tipped with a specific shape impactor [26,27]; (3) electronic fruit or impact recording devices [28-30]. However, the main problem with these methods is that vibrations make it difficult to accurately record force and deformation during impact due to shorter time periods to observe the mechanism. Therefore, high-speed cameras are more frequently used to observe quality and damage for impact and vibratory research into different fruits [8,21,30-34]. Impact damage is mainly caused by the factors such as the type of packaging surface onto which the single stem fruit drops, drop height, and the velocity at the moment of collision [35-40]. However, impact damage for single fruits is totally different from cluster fruits because cluster fruits are gripped and cut from the main rachis. Therefore, vibration transmissions during transportation and excitation transmissions due to the impact of packaging surfaces on the cluster fruits are totally different from single stem fruits.

The post-harvest operations affect the quality of table grapes through direct contact with packaging materials and machine components. A large quantity of table grapes is wasted just because of damage such as berry fall and fruit decay. Berry fall or decay is mostly caused by impact loads during the mechanical handling, packaging, storage, and transport of table grapes [41]. During fresh fruit transport and handling, dynamical loads cause, by far, the most fruit decay and shatter damage because these loads are higher in incidence and magnitude than static loads $[42,43]$. The berry drop (shatter) of the grape cluster during and after harvest is related to its physiological process and physical function. Vibration and impact in each operation can lead to fruit stalk detachment. There are three categories of grape berry drop: (1) berry shatter, which consists of a detachment of berries 
from the main rachis due to the fragile tissue structure of the stalk; (2) wet drop, that is, berries are sloughed from the stems and attached to the pedicel because of the short and thin berry brush [44,45]; (3) dry drop or abscission, which is caused by the formation of an abscission zone (AZ) in the grape, which develops at the junction between the pedicel and berry [4].

At present, chemical methods are widely used in the grape industry to solve the problem of grape berry drop and berry decay [46-49]. However, in recent years, more and more attention has been paid to non-chemical methods. Researchers have been trying to explore the relationship between mechanical harvesting and berry damage to optimize mechanical handling methods for the reduction of berry fall and berry damage. For instance, Pezzi et al. used an electronic fruit to investigate the collision of fresh grapes during mechanical harvesting and transportation [50,51], and Yue et al. found that the drop impact of grape berries has significant effects on physiological quality during storage and transportation [52]. Bian et al. studied the influence of drop height on the dielectric properties of red globe grapes [53], and Vinokur et al. found that the berry fall rate is directly proportional to the free-fall height [41]. Jung et al. evaluated the effect of vibration stress on the quality of packaged grapes by simulated transportation [2], and Vallone et al. measured the effect of mechanical harvesting of grapes using an instrumented sphere [54]. Deng et al. developed a mathematical model that predicts grape berry drop during storage [4], and Fischer et al. determined the critical frequencies for grape and strawberry fruit shattering during transportation for distribution $[55,56]$. Lu designed tests, such as an emergency stop test in vertical fall, to observe the fruit collision of grape clusters with a piezoelectric film [57], and Hao et al. found that the greater the vibration acceleration, the greater the damage to Kyoho grapes during storage and road transportation [58]. Demir et al. calculated the natural frequency of grape and berry drop during simulated transportation [59]. The above studies deal with the collision between single berries and placing surface and the effect of drop height on berry damage. However, the impact of mechanical load on harvest and post-harvest quality and berry drop of fresh grape clusters in term of vibration has still many research gaps.

Grape cluster vibration plays a vital role in the process of mechanical harvesting and post-harvest handling of table grapes because it will cause berry fall and berry damage. To explore the influence of excitation on vibration, a simulation modeling method is very important, in addition to experimental methods. Simulation can help us to study the transmission route of the excitation and vibration of the cluster. Additionally, simulation can help us to realize the effect of mechanical handling on the grape cluster. To find out the vibration range under different conditions, Kondo et al. designed a low-speed tomato vibrating test system and modeled the panicle tomato [60], and Liu et al. found that acceleration and deceleration are the reasons for vibration in grape fruit clusters; they also found the relationship between the angle deviation of the grape cluster and the excitation transmission through a high-speed camera [61]. Liu et al. designed a compound mechanical model of grape clusters and carried out simulation and experimental analyses under different excitations in horizontal transportation to observed the swing angle of each berry [8]. Faheem et al. found the relationship of the swing angle of clusters with hanging force during linear robotic transportation of the whole grape cluster at different excitations [62]. No specific studies have been done on the impact of packaging materials and the effect of the cluster's vibration on the berry drop mechanism during robotic vertical transportation and placing of the whole grape cluster.

The damage due to the impact and vibration of the grape cluster has a significant effect on control losses during robotic post-harvest handling on the industrial as well as farm level. In this context, the main purpose of the study is to analyze the berry dropping mechanism during vertical transportation and the placing of the whole grape cluster. The behavior of the grape cluster's berries and the hanging force signals (the force that bears the weight of the gripped grape cluster against gravity during robotic transportation) under different speed and acceleration excitations were observed and analyzed. The effect of 
different packaging materials on the berries from the top and bottom sides of the cluster was analyzed using a high-speed video camera. Additionally, the relationship of the cluster's mass with forces before and after the impact was analyzed to understand the berry drop mechanism. Overall, this study provides theoretical support to the industries by optimizing the berry falling loss of different cluster fruits during robotic post-harvest handling and suggests a safe packaging material and excitation at which the cluster vibrates with less magnitude. Hence, berry drop will be reduced.

\section{Materials and Methods}

\subsection{Structure of Fresh Grape Clusters}

Cluster fruits have some special features compared to single-stem fruits. Fresh table grapes develop as clusters (bunches), with each berry attached to the pedicel through rachis and sub rachis, which contain vascular bundles (also known as the cap stem). The stem unites the berry with the rachis, as shown in Figure 1. This union is very important to avoid loss of berries (dropping or shattering) [62].

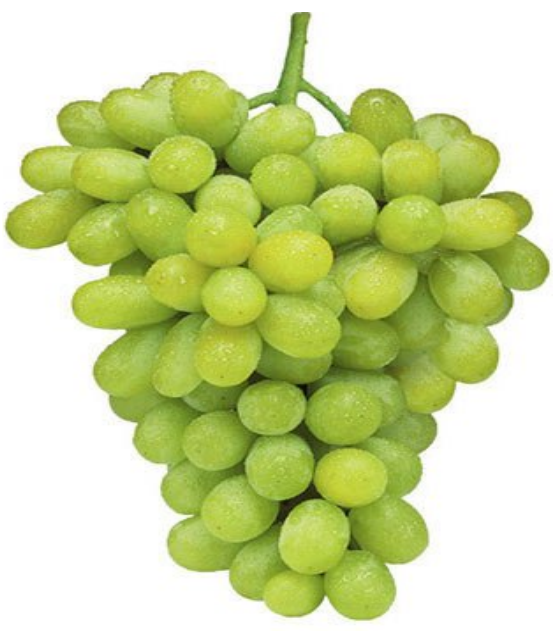

(a)

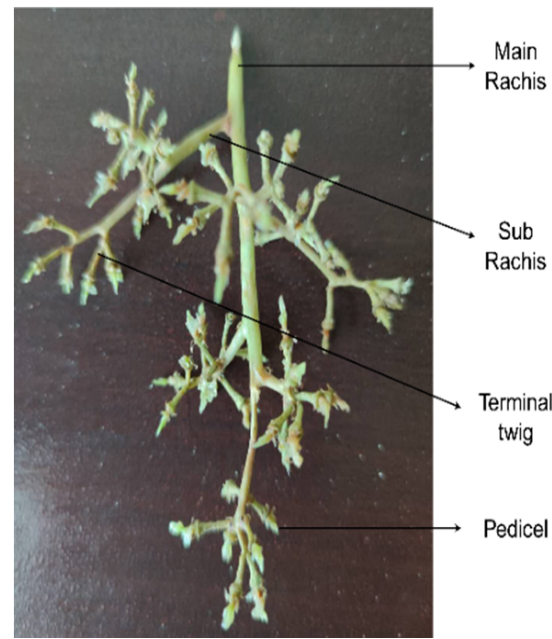

(b)

Figure 1. Structure of table grape cluster with and without berries. (a) Table grape cluster; (b) stalk fruit structure.

\subsection{Different Excitations and Behaviour of Grape Cluster Fruit during Robotic Transportation and Placing}

When a grape cluster is transported towards a box after harvesting, the excitation is mainly caused by the start-stop of the mechanical system that transfers the gripper to the main rachis of the grape cluster, when the position of the main rachis of the cluster deviates from the point parallel to the gripper, as shown in Figure 2. Thus, the grape cluster starts to vibrate, and bending of the main rachis happens. In the operation of speedy robotic transportation, this bending of rachis would cause a severe load on the pedicel. When the load exceeds the connection strength, then the berry fall starts. During the speedy robotic placing of the grape cluster into the box, excitations come from the packaging materials, which is transmitted into the whole cluster, as shown in Figure 2. These excitations apply a load on the connection point between the pedicel and the berry so that berry shattering happens. Thus, the berry shatter of grape clusters is a highly complex problem of multiple loads during the whole robotic transportation placing cycle. Therefore, in this paper, the main focus is to analyze the vibration behavior of hanging grape clusters during vertical robotic transportation and placing cycles. The effect of different speed and acceleration excitations on the cluster during vertical transportation and the impact of different packaging materials on the cluster were observed and analyzed. 


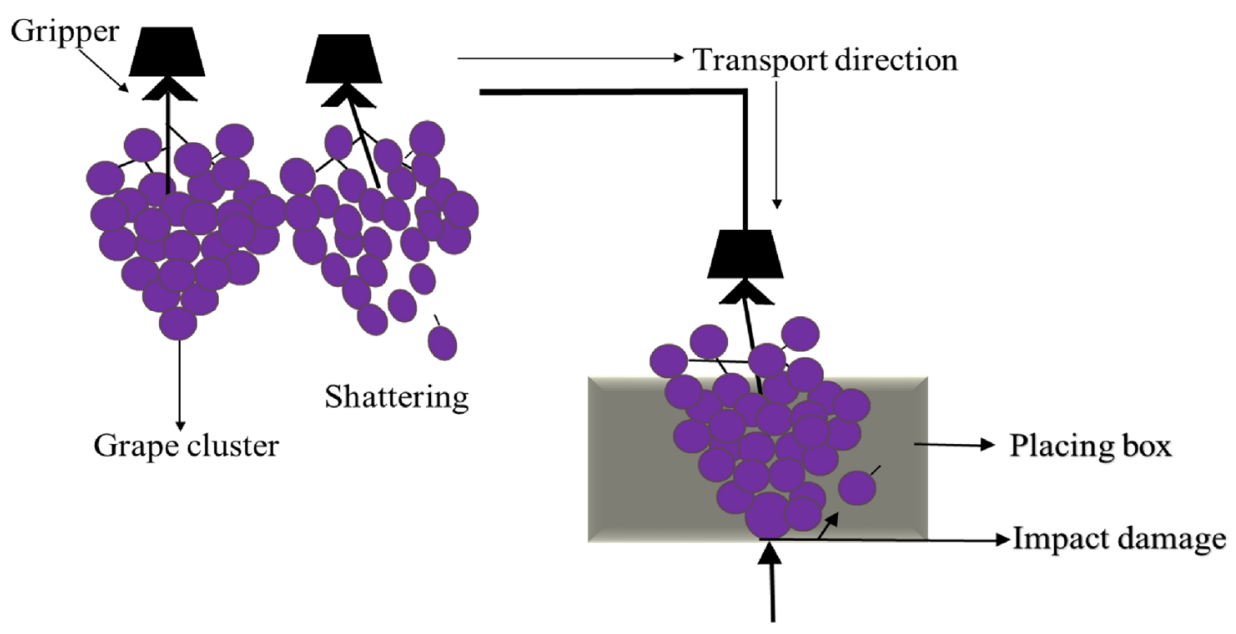

Figure 2. Different excitation transmissions and damage of grape cluster fruit during robotic transportation and placing cycles.

\subsection{Experimental Materials}

The experiment was carried out in the Key Laboratory of Modern Agricultural Equipment Engineering, designated by the Ministry of Education, Jiangsu University, Zhenjiang, China. Three artificial grape clusters with different shapes and masses $(0.48,0.50,0.53$ $\mathrm{kg}$ ), measured with a digital weight balance (BP Professional Electronic Balance BP-6228, accuracy $0.01 \mathrm{~g}$ ), were used as experimental materials. There were about 70 to 80 berries in each cluster that were filled manually with soil to maintain a similar mass to that of real berries, and each berry mass was 0.005 to $0.007 \mathrm{~kg}[63,64]$. Since the real cluster will be damaged in experiments under different speeds and accelerations, which will lead to a change in conditions, the results of different excitation treatments cannot be put together to compare and analyze [62]. For 40 years, artificial fruits have been built similar to real agricultural produce in order to measure the mechanical load caused by harvest and postharvest handling systems [30]. Three different packaging materials-(a) a rigid plastic box, (b) a corrugated fiberboard box, and (c) an expandable polystyrene box-were used for the experimental placing test [35]. The experimental setup and materials are shown in Figure 3. A lead screw lathe with a fabricated 1 DOF (degree of freedom) actuator, a gripper, and a single-axis force sensor (model: MIK LCS1; weight range $0-5 \mathrm{~kg}$ with $0.03 \% \mathrm{FS}$ ) that was fixed in between the gripper and the hanging grape cluster were used for the measurement of magnitude of the cluster's vibration in terms of forces acting on the grape cluster before and after the impact in real-time. The behavior of grape cluster movement during and after the impact with the packaging materials was recorded with a high-speed camera system (Olympus, i-speed LT), as shown in Figure 3a [65]. The camera system was adjusted to 1000 fps (frames per second), with a black and white screen and a light source for high visibility. It was placed at a distance of $3.5 \mathrm{~m}$ from the hanging grape cluster. 


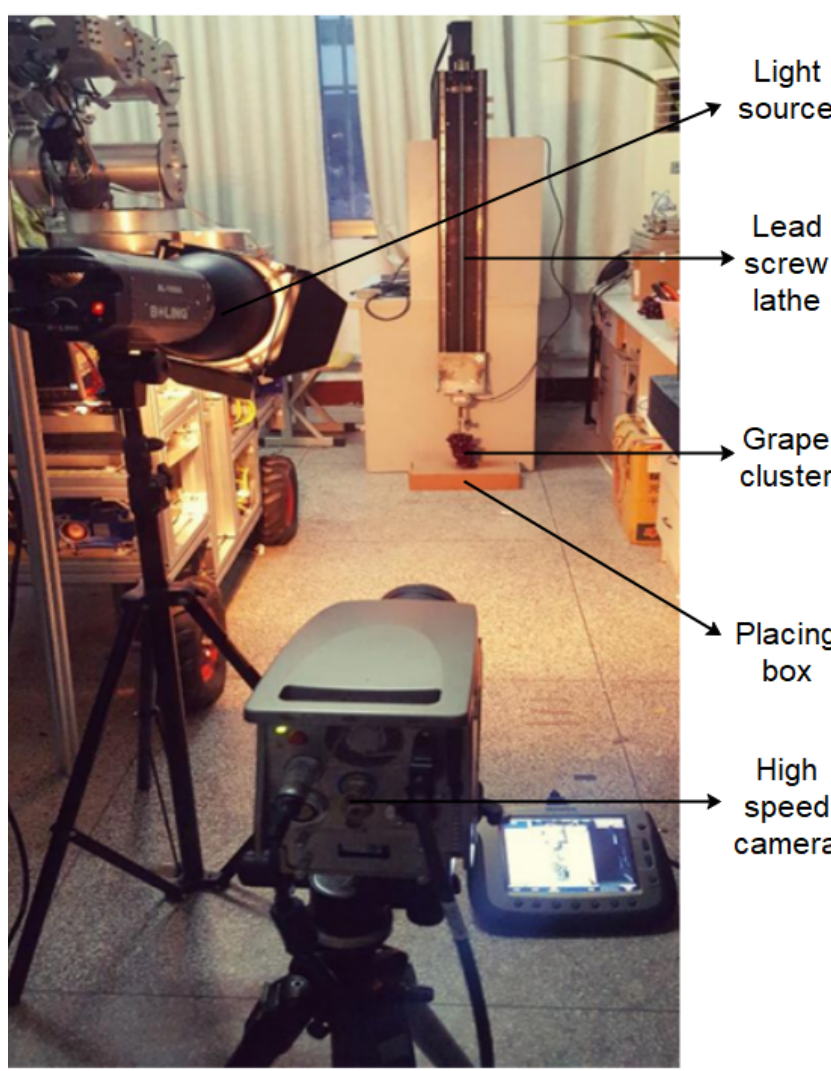

(a)

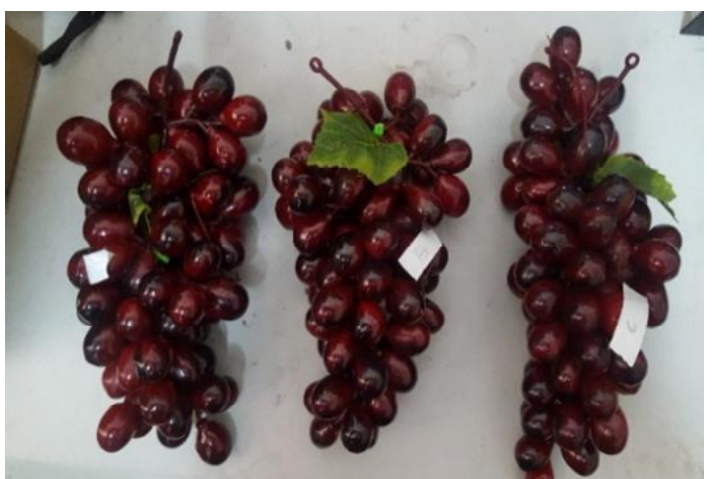

(b)

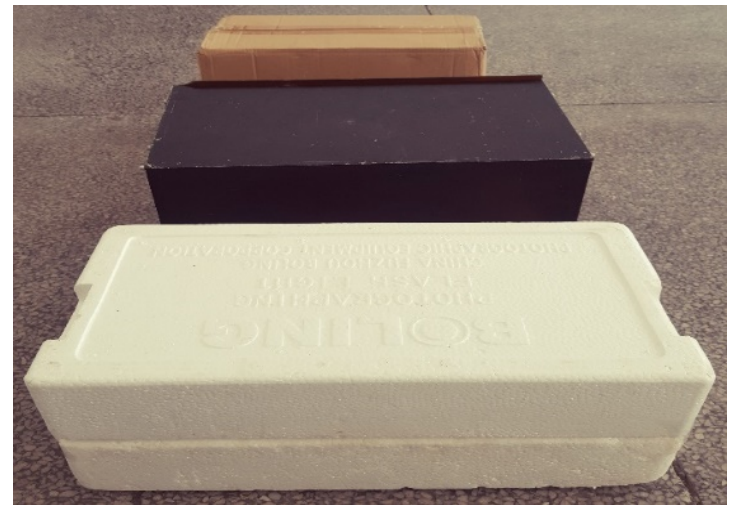

(c)

Figure 3. Experimental materials: (a) experimental setup; (b) 3-grape clusters; (c) 3-packaging materials.

\subsection{Experimental Methods}

\subsubsection{Vertical Transportation of Grape Cluster}

Three different grape clusters were used as an experimental material because the study's aim was to analyze the vibration mechanism of the hanging grape cluster in different zones of vertical transportation, which was difficult to do using real grape clusters. For understanding the berry drop mechanism of grape clusters due to vibration, an actuator is moved linearly on the rails of the lead screw lathe according to the input speed and acceleration excitations from the PLC (programmable logic control), as shown in Table 1. A vertical start and stop transportation test setup of grape clusters was constructed, as shown below in Figure 4a. Due to the actuator movement, the excitations are transferred from the gripper towards the berries through the main rachis, and the hanging grape cluster starts to vibrate. The magnitude of the cluster's vibration during vertical transportation is determined from the force sensor signals. The excitation displacement or stroke length was adjusted to $0.8 \mathrm{~m}$ from the start to the stop point [62]. Additionally, the vibration characteristics of the grape clusters during the different phases of vertical transportation were analyzed. 
Table 1. Different excitation treatments applied to the actuator for the transportation of grape clusters.

\begin{tabular}{cccc}
\hline Speed $(\mathbf{m} / \mathbf{s})$ & Accelerated Speed $\left(\mathbf{m} / \mathbf{s}^{2}\right)$ & Accelerated Time $(\mathbf{m s})$ & Duty Cycle $(\mathbf{s})$ \\
\hline \multirow{3}{*}{0.4} & 6 & 66.66 & 2 \\
& 8 & 50 & 2 \\
& 10 & 40 & 2 \\
0.6 & 12 & 33 & 1.33 \\
& 6 & 100 & 1.33 \\
& 10 & 75 & 1.33 \\
0.8 & 12 & 60 & 1.33 \\
& 6 & 50 & 1 \\
& 8 & 133 & 1 \\
& 10 & 100 & 1 \\
& 12 & 80 & 1 \\
\hline \multirow{3}{*}{1} & 6 & 66 & 0.8 \\
& 8 & 166 & 0.8 \\
& 10 & 125 & 0.8 \\
& 12 & 100 & 0.8
\end{tabular}

Note: A duty cycle is the time taken by the actuator to complete one stroke (stroke/time) from the start to stop positions.

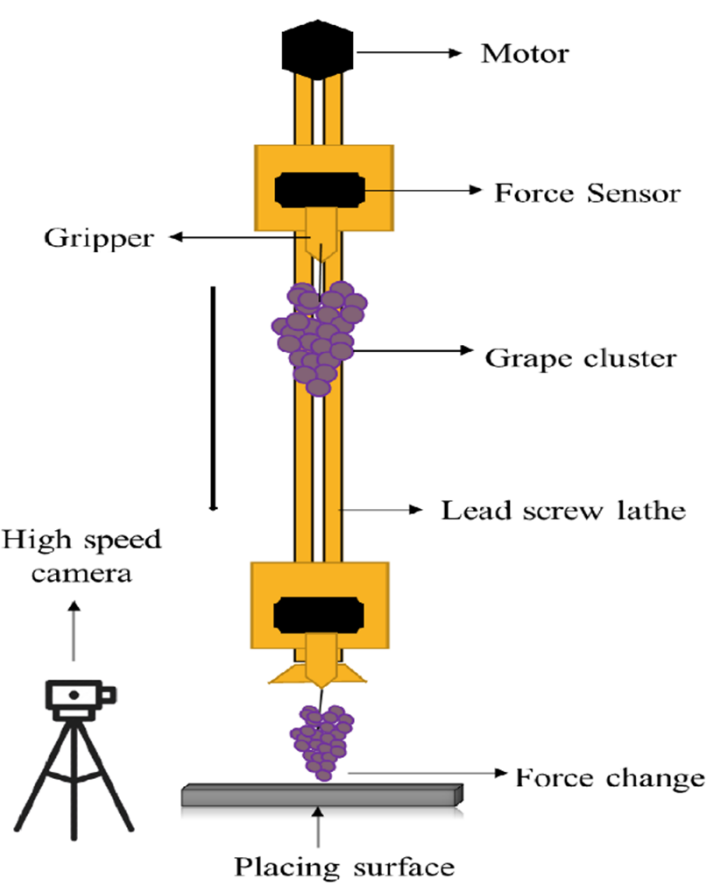

(a)

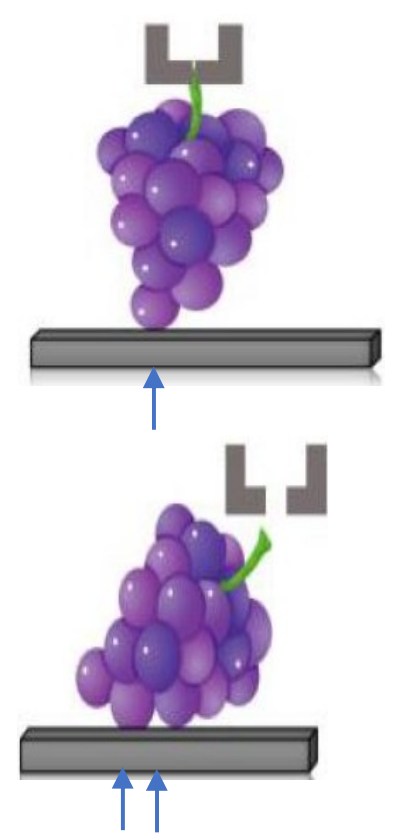

(b)

Figure 4. Vertical start and stop transportation placing cycle: (a) vertical transportation; (b) placing view.

\subsubsection{Placing of Grape Cluster}

Three different packaging materials (rigid plastic box, corrugated fiberboard, expandable polystyrene) were used to measure the change in force signals during the robotic placing of the grape cluster. The deflection of the berries during placing and the state of the whole grape cluster were observed from the videos and images of a high-speed camera, as shown in Figure 4a. The mechanism of the grape cluster berry drop was observed and explained from these videos and images. The main rachis of the grape cluster was fixed in a gripper, different speed and acceleration excitations were transmitted to the actuator, 
and it moved from the start to the stop position. In the robotic placing phase of the grape cluster, the excitation comes from the placing surface, which is measured by the single-axis force sensor, as shown in Figure $4 \mathrm{~b}$. During these treatments, the change in force signals during the placing of the three grape cluster samples with different masses $(0.48,0.50,0.53$ $\mathrm{kg}$ ) was also determined. The behavior of the top berry and the bottom berry was also observed accordingly; the safest packaging material and excitation treatment, at which there are low chances of berry deflection or berry fall, were realized.

\section{Results}

The behavior of the grape cluster during vertical transportation and placing was observed. The details of the results obtained from the experiments are explained in the following sections.

\subsection{Vibration Characteristics during Vertical Transportation and Placing of Grape Cluster}

Based on the force signals, the vibration characteristics of the grape cluster during vertical transportation and placing under different excitations are observed in this section. The details of the vibration characteristics of the grape cluster and its berries are explained in the subsequent sections.

\subsubsection{Different Stages of Vertical Transportation}

Due to the actuator movement from the start position to the stop position, as shown in Figure $5 \mathrm{a}$, the hanging grape cluster started to vibrate, and the magnitude of the cluster's vibration in terms of hanging force was measured. Hanging force was measured in the form of analog signals. These force signals of the hanging cluster during vertical transportation and placing were divided into 5 phases, as shown in Figure $5 b$, for a better understanding of the dropping mechanism or berry deflection of the hanging grape cluster at different speed and acceleration excitations.

1. Phase 1 (stationary phase of the grape cluster): In this phase, the force signals showed that the hanging grape cluster is in the stationary position with its static weight (calibrated value of the hanging grape cluster).

2. Phase 2 (accelerating phase): In this phase, when excitations were applied to the actuator (IDOF manipulator), it started to move, and the hanging grape cluster suddenly vibrated due to the movement of the actuator. Hence, the magnitude of the force signals is observed as high in this phase due to the high vibration of the cluster.

3. Phase 3 (constant speed phase): In between Phase 2 and Phase 4 , the force signal curve depicts that the cluster vibrates with constant amplitude due to the short interval of time.

4. Phase 4 (deaccelerating phase): In the next phase, when the actuator was going to stop, a dramatic decrement in the magnitude of the force signals was observed, which shows the hanging grape cluster has reached a minimum position (lowest position) during the stop phase of the actuator's motion. This is due to the excitation coming from the packaging surface to the whole cluster, which causes an impact on the whole cluster; the berries started to deflect in this phase.

5. Phase 5 (placing phase): After the stop of the actuator in Zone 5, all the excitation energy comes from the packaging material storing the grape cluster; the impact with the grape cluster becomes the reason for the berries falling and the bending of the main rachis. 


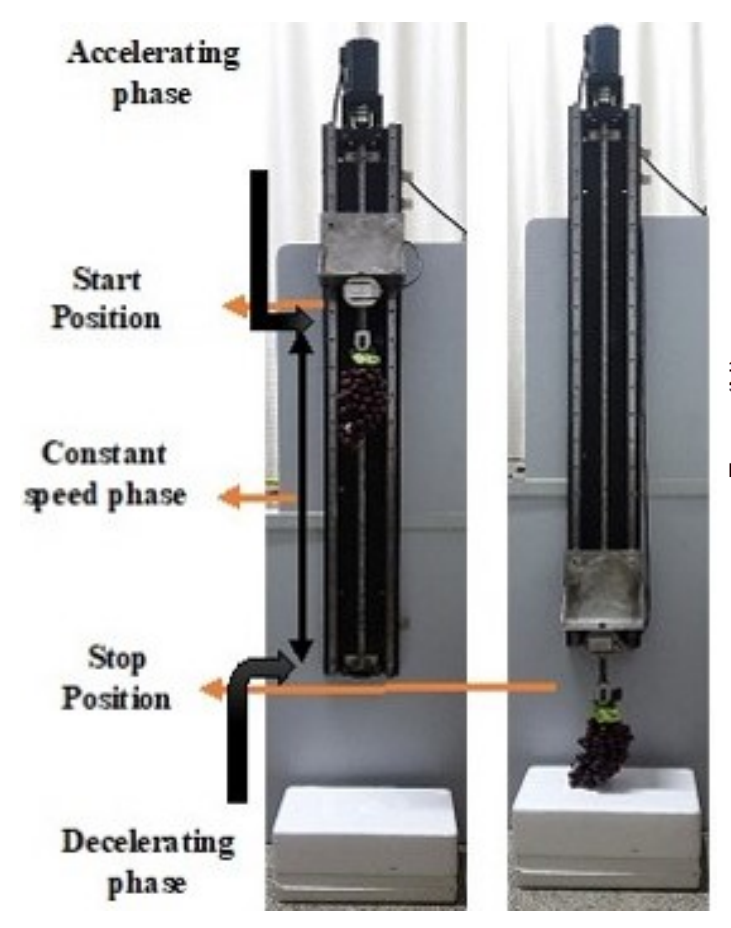

(a)

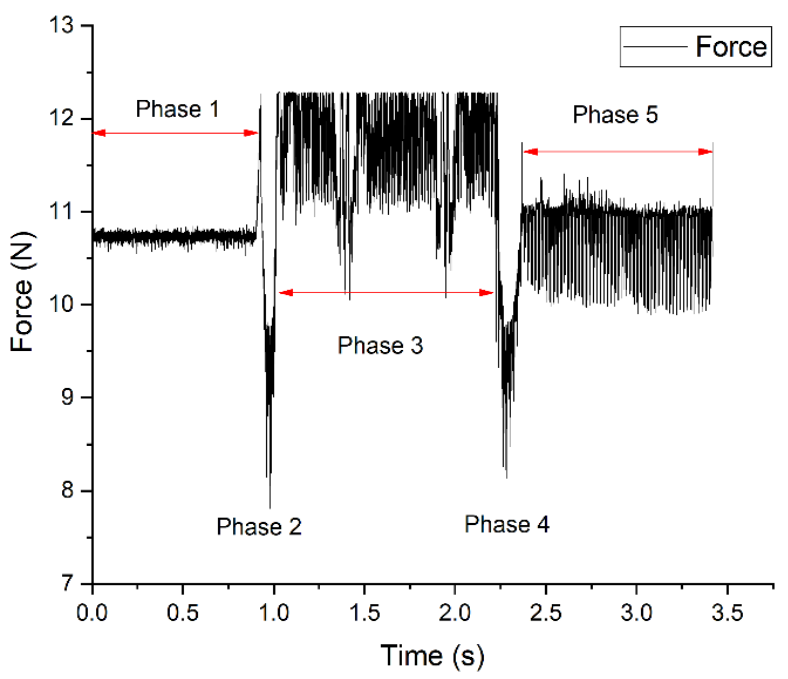

(b)

Figure 5. Vibration characteristics of the grape cluster during vertical transportation: (a) phases of the grape cluster; (b) force signals.

\subsubsection{Different Excitation Transmissions during Placing}

It is difficult to observe the deflection mechanism of berries during vertical transportation and placing with the naked eye due to the short interval of time. Therefore, a high-speed camera was used to analyze the deflection of berries at different excitations during the transportation placing cycle, as shown in Figure 6. When the grape cluster collides with the packaging surface, the excitation moves from the packaging material to the whole grape cluster, which causes damage in the form of berry fall and decay. There are two types of berry dropping mechanisms observed from the high-speed photography images during the placing of the grape cluster at different speed and acceleration excitations [8] applied to the hanging grape cluster, as defined below. Excessive bending of the main rachis was observed during the robotic placing of the grape cluster. The impact of the packaging surface on the whole grape cluster after contact was divided into two categories, as shown in Figure 6c.

\section{Bottom Berries}

The impact excitation comes from the packaging materials after the collision, which caused the deflection of the bottom barriers due to the torsional load in between the berry and the pedicel.

\section{Top Berries}

Excitations are transmitted to the whole cluster after striking the packaging materials, and upper barrier deflection was observed due to the vibration or bending of the main rachis. 


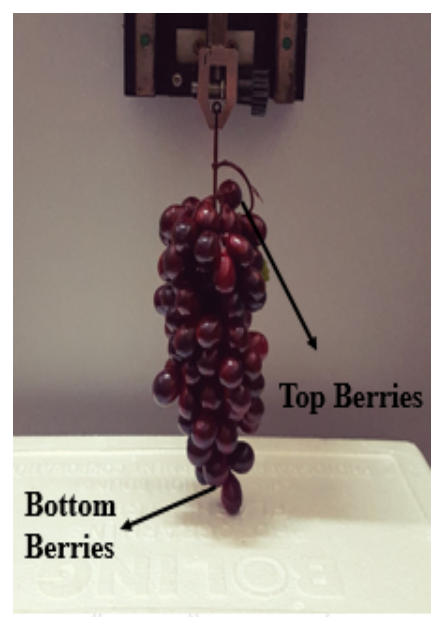

(a)

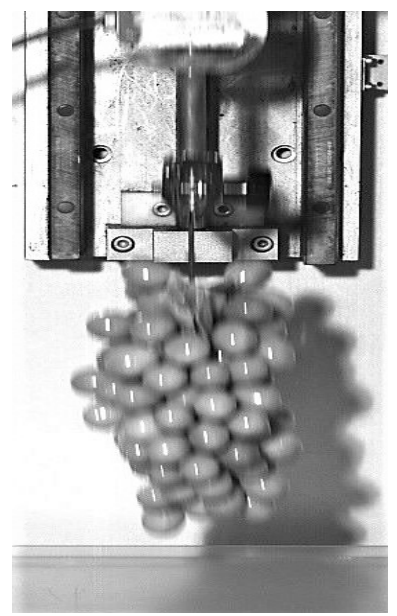

(b)
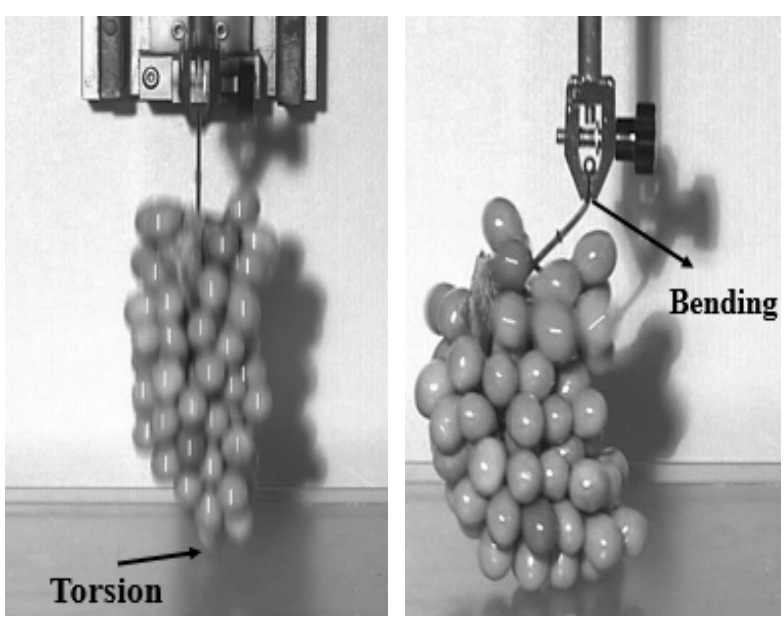

(c)

Figure 6. Load on the berries of the grape cluster during the placing phase: (a) grape cluster; (b) transportation load; (c) placing load.

\subsection{Effect of Different Factors on Vibration Signals}

In this section, the effect of different factors such as speed, acceleration of the actuator on the vibration signals of the grape cluster during vertical transportation is studied. The experimental effect of different packaging materials on the grape cluster at different speed and acceleration excitations is explained. Additionally, the effect of the cluster's mass on berry deflection during vertical transportation and placing is analyzed. The details about the effect of these factors on the vibration signals are given in the subsequent sections.

\subsubsection{Effect of Different Speeds during Vertical Transportation}

Figure 7 shows the force signals of the hanging grape cluster during different phases of vertical transportation under different speed excitations $(0.4,0.6,0.8,1.0 \mathrm{~m} / \mathrm{s})$. Based on the results, the magnitude of force for the grape cluster was observed at maximum at the start position (acceleration of the actuator) for four speeds, i.e., 12.2, 12.25, 12.28, 12.4 N. This was due to the sudden excitation coming from the actuator and transmitted towards the hanging grape cluster at the start; the cluster vibrated with high magnitude. Additionally, the magnitude of force increases with an increase in the speed of the actuator. It was observed from Figure 7 that the force signals suddenly decreased because gravity helped to reduce the weight of the cluster. After that, the signals showed that the cluster moved downward with constant speed and collided with the packaging material. After colliding with the packaging surface, the force signals suddenly became low because the excitation that comes from the packaging surface was transmitted to the whole cluster. Then, force signals showed some fluctuations after the impact due to the deflection of the cluster, and, at last, the force signals showed that the cluster reached the stop position, which showed the calibrated value of the grape cluster. These results suggest that the accelerating phase of the actuator caused the vibration of the cluster and more berry drop at this phase of robotic vertical transportation of the grape cluster. 


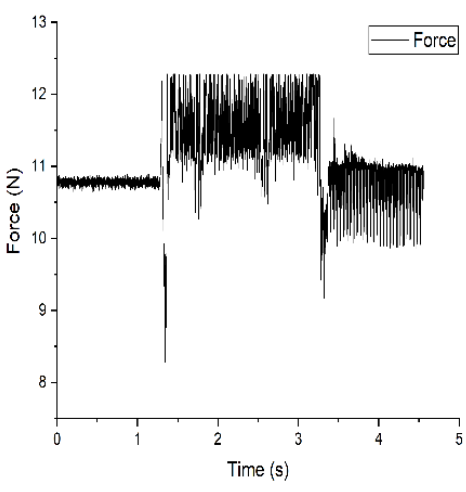

(a)

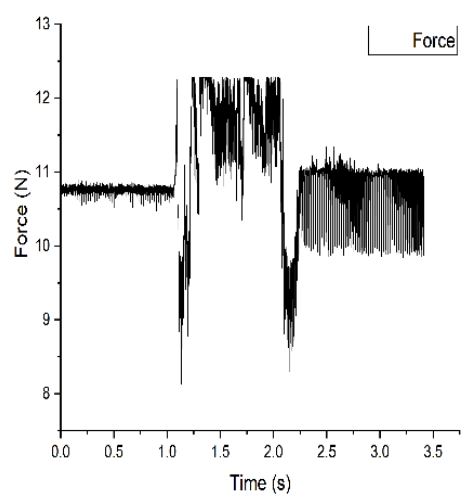

(c)

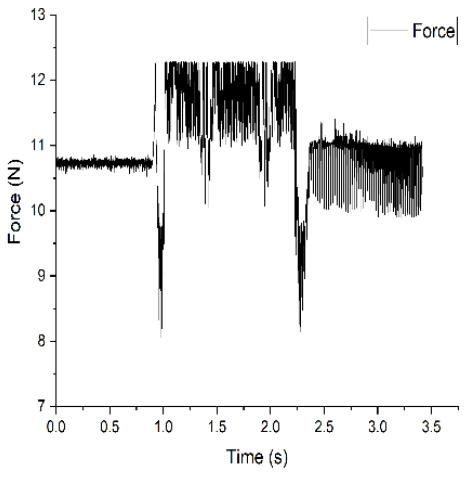

(b)

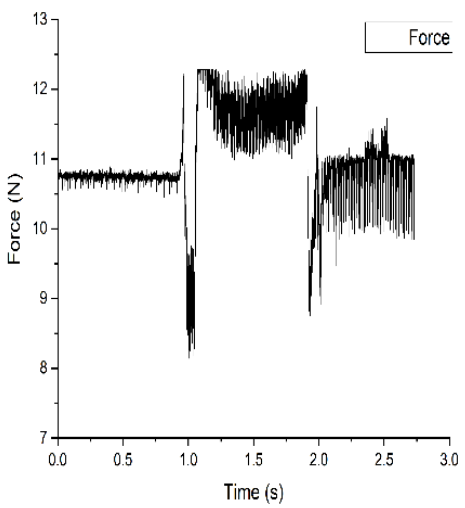

(d)

Figure 7. Effect of different speeds on the force of the grape cluster during vertical transportation test: (a) $0.4 \mathrm{~m} / \mathrm{s}$; (b) $0.6 \mathrm{~m} / \mathrm{s}$; (c) $0.8 \mathrm{~m} / \mathrm{s}$; (d) $1.0 \mathrm{~m} / \mathrm{s}$.

\subsubsection{Effect of Acceleration Excitations during Vertical Transportation}

It was observed from the experiments that at input acceleration excitations $(6,8$, $\left.10,12 \mathrm{~m} / \mathrm{s}^{2}\right)$, the amplitude of the cluster's vibration was maximum at the start of the actuator movement. It was due to the sudden motion of the actuator and the friction of the guide rails [66] on which the actuator moves. It was observed, secondly, from the experimental analysis, that the magnitude of the cluster's hanging force in the starting phase of the actuator was positively correlated with the input acceleration and mass of the cluster. The magnitude of hanging force was observed to be high at the acceleration excitation of $12 \mathrm{~m} / \mathrm{s}^{2}$ at the following speeds of the actuator, i.e., $(0.4,1.0 \mathrm{~m} / \mathrm{s})$, as shown in Figure 8. It was also observed from the experimental analysis that the optimized acceleration excitation was $10 \mathrm{~m} / \mathrm{s}^{2}$, at which the deflection of the berries was minimum. This is due to the cluster swinging in one direction, with minimum twisting of the main rachis. Therefore, the chances of berry deflection will be minimized. These results suggest that the acceleration phase causes serious vibrations of the grape cluster during robotic vertical transportation, and more berry deflection occurs in this phase. In robotic vertical transportation, the acceleration excitations did not affect the vibration of the grape cluster too much, so the cluster's vibration is always low in vertical downward transportation compared to horizontal transportation of the hanging grape cluster, as measured in our previous research [62]. 


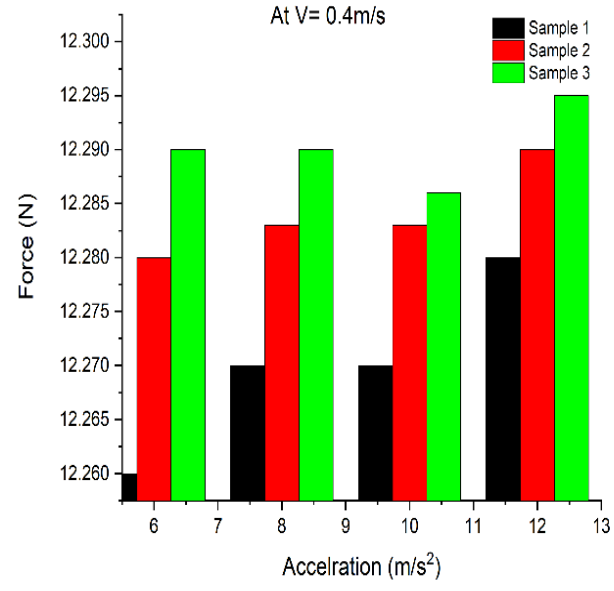

(a)

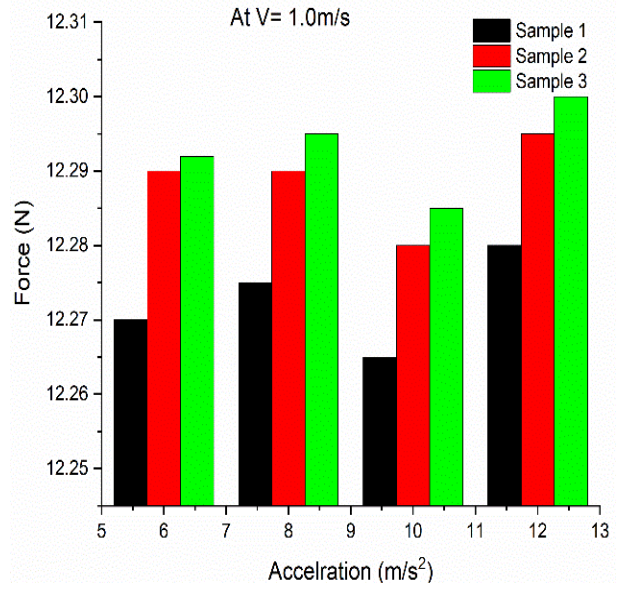

(b)

Figure 8. Effect of acceleration excitations on the peak force of the cluster during vertical transportation at different speeds, such as (a) $0.4 \mathrm{~m} / \mathrm{s}$; (b) $1.0 \mathrm{~m} / \mathrm{s}$.

\subsubsection{Effect of Packaging Materials on the Berry Deflection of Cluster}

In the placing phase of the grape cluster, the time interval of the stop or deaccelerating phase of the actuator was too short, so the berry dropping mechanism of the whole cluster could not be observed properly. Therefore, a high-speed photography camera was used for the analysis. It was observed from the high-speed photography images that the deflection of the cluster's berries in terms of torsion from the bottom and bending from the upper side increases with an increase in speed and acceleration excitations of the actuator. It was also observed from Figure 9 that the effect of the rigid plastic box on the deflection of the upper and lower berries was at a maximum, and it showed small force signals, i.e., $8.8 \mathrm{~N}$, compared to expandable polystyrene and corrugated fiberboard boxes $(9.6$ and $9.35 \mathrm{~N})$. This is due to the maximum excitations that transmit from the rigid box surface towards the whole grape cluster. It can also be seen from Figure 9 that the fluctuations in the force signals are more after striking with the rigid plastic box due to the large deflection of the whole cluster. These force signal results indicate that the choice of packaging materials can significantly reduce the possibility of berry drop damage during the robotic placing of cluster fruits.

(a)

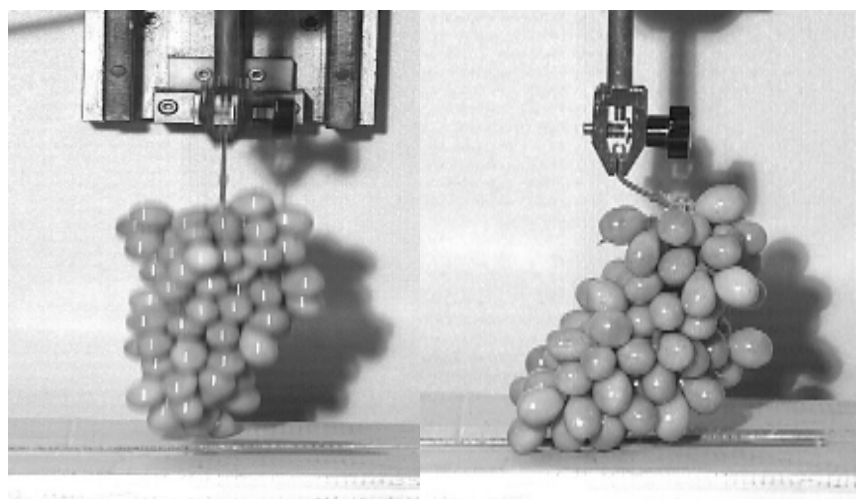

Figure 9. Cont.

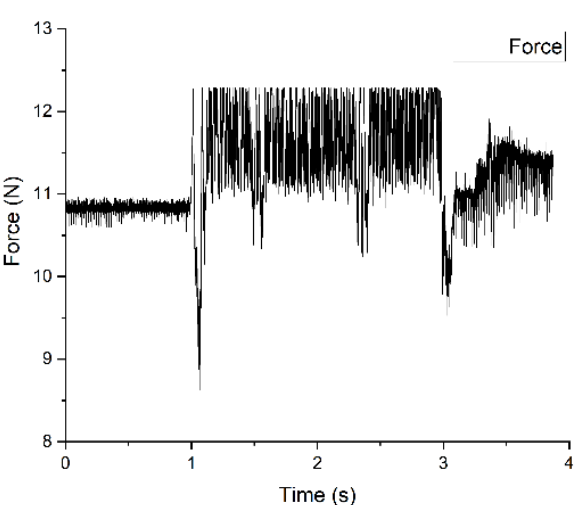


(b)

(c)
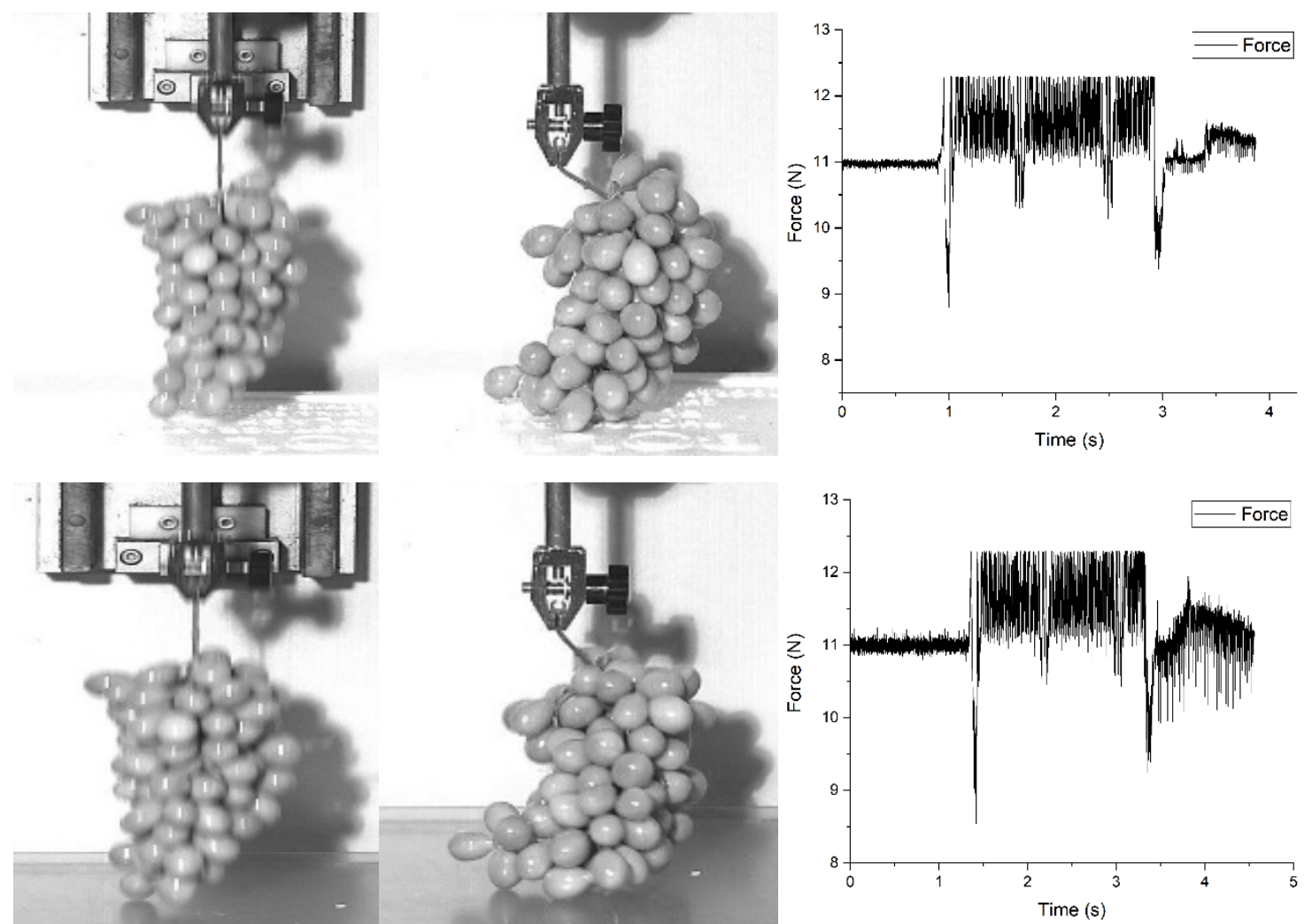

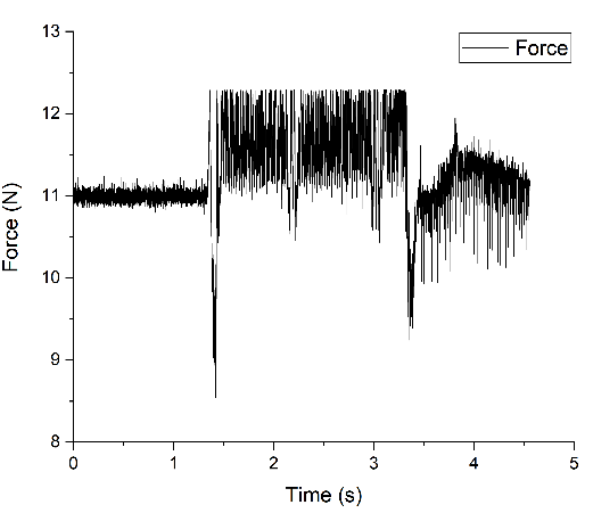

Figure 9. High-speed camera-based determination of cluster deflection and force signals after striking with different placing materials: (a)force change signals with corrugated fiberboard; (b) force change signals with expandable polystyrene; (c) force change signals with a rigid plastic box.

\subsubsection{Effect of the Cluster's Mass on Berry Deflection during Placing}

Figure 10 shows the high-speed camera images of three different grape clusters $(0.48$, $0.50,0.53 \mathrm{~kg}$ ) during placing on a rigid plastic box, along with the corresponding results of the force sensor. According to the results, with the increment in the mass of the grape cluster, the deflection of the berries was observed to be less. This was due to the excitations absorbed by the grape cluster after colliding with the packaging material; it decreased with the increase in the mass of the cluster. The grape cluster with a mass of $0.48 \mathrm{~kg}$ showed the maximum change of force or load, i.e., $8.20 \mathrm{~N}$ from the calibrated force value of that sample, $10.8 \mathrm{~N}$ after colliding with the rigid plastic box, as compared to two other grape cluster samples with different masses, i.e., 0.50 and $0.53 \mathrm{~kg}$, with changes in force signals of 8.75 and $9.28 \mathrm{~N}$. The calibrated force of these two cluster samples was 11 and $11.15 \mathrm{~N}$ respectively. These results suggest that fruit mass is an important component of the momentum that affects the detachment forces of the berries; the higher the fruit mass, the higher the momentum and hang force, and the lower the berry shattering during placing due to the compactness of the berries. 
(a)

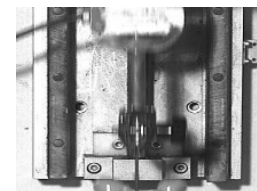

(b)
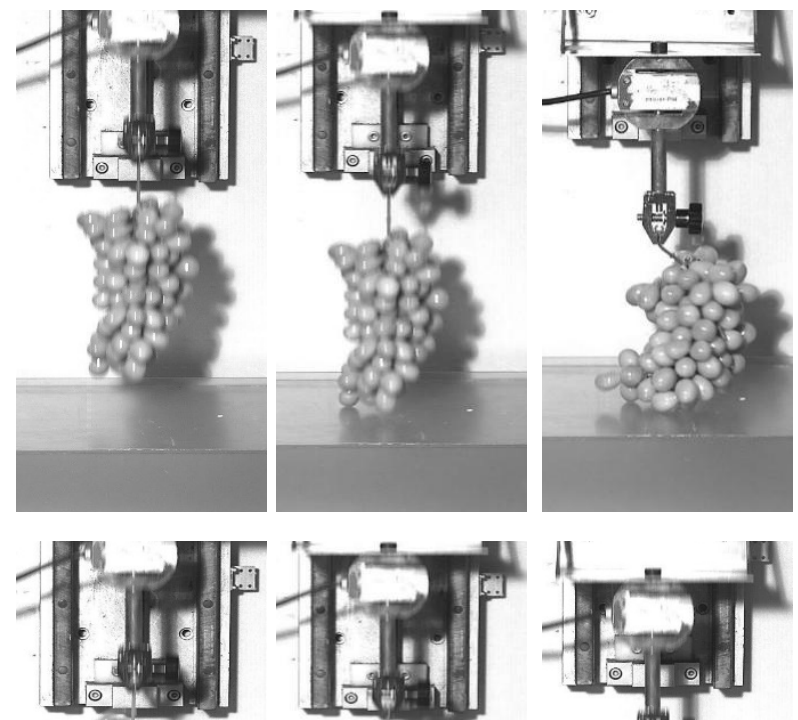

(c)
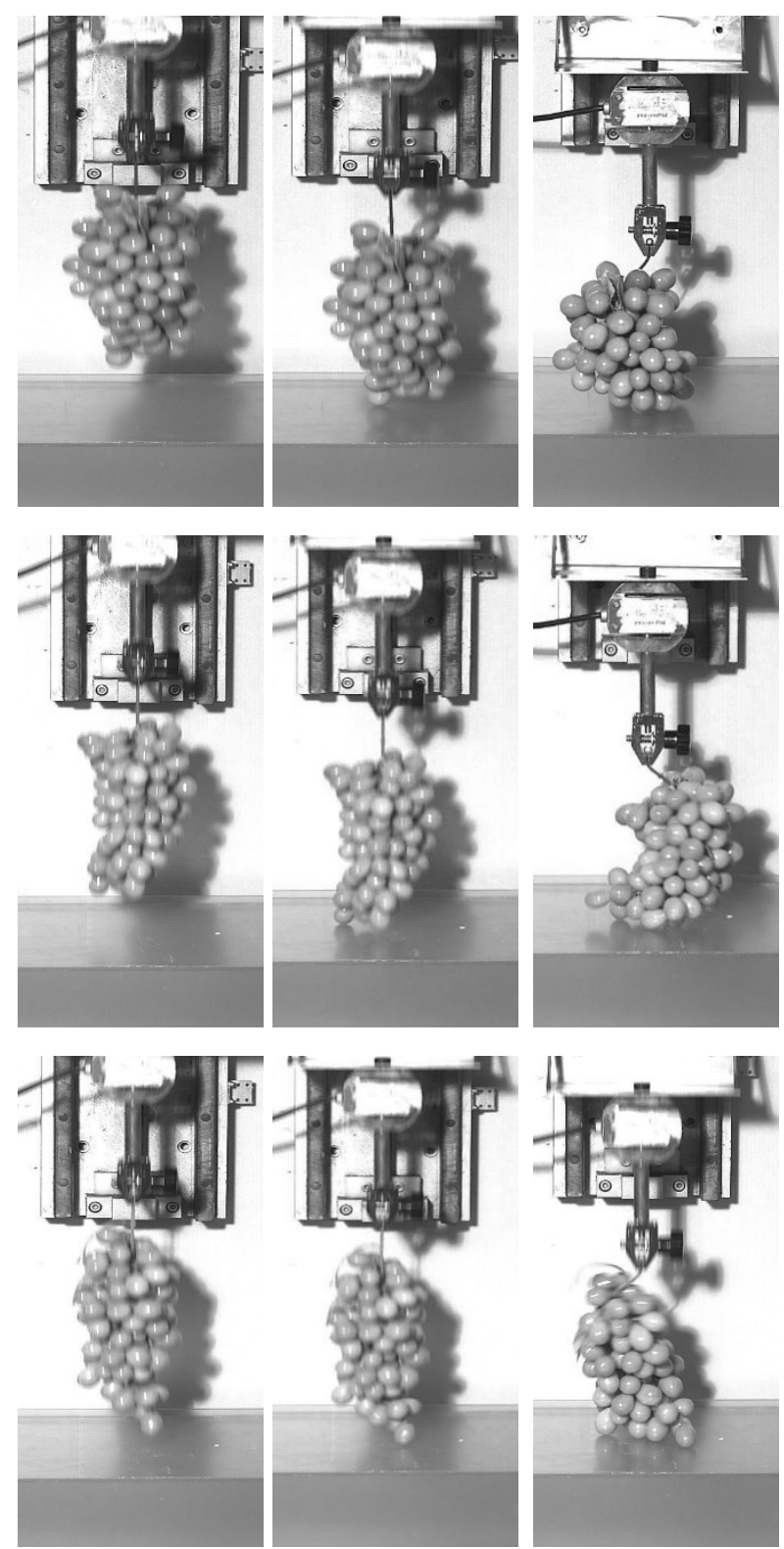
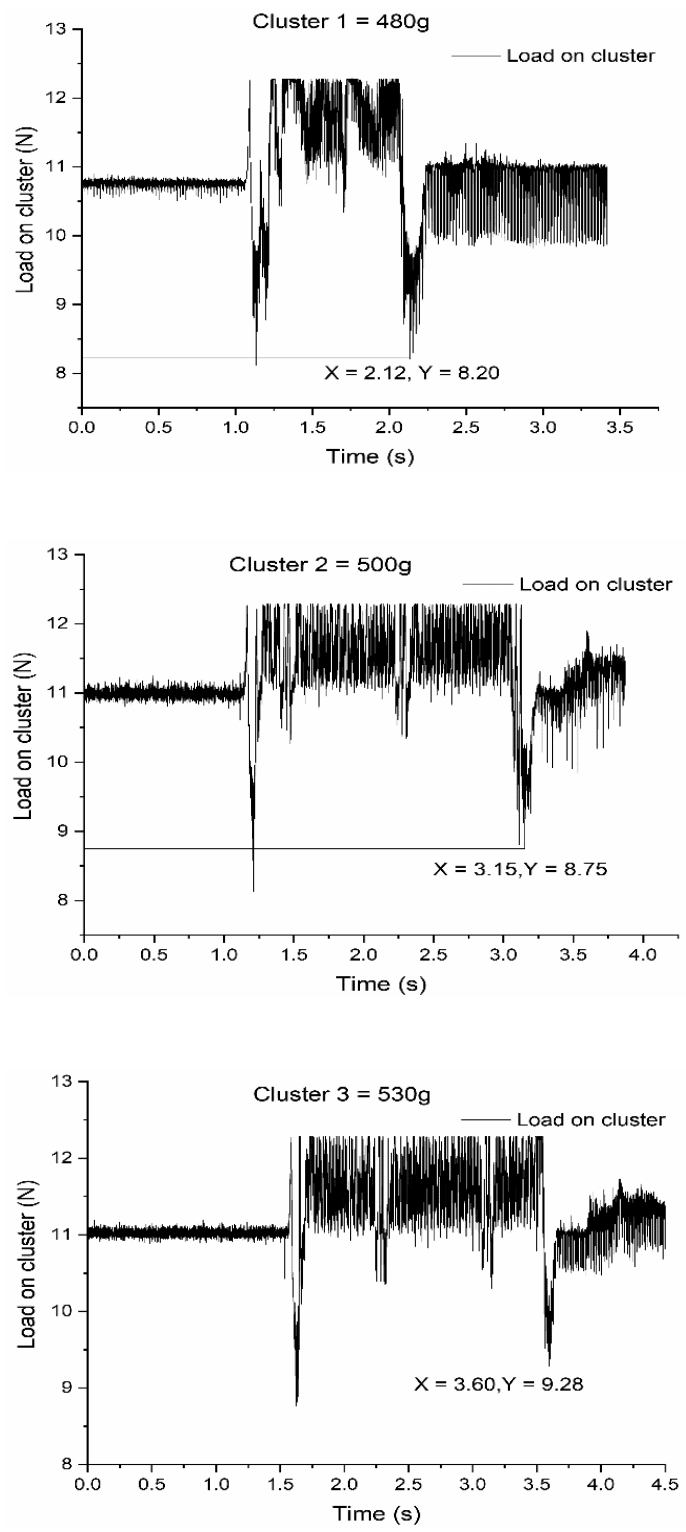

Force signal for three different clusters

Figure 10. Effect of the cluster's mass on force change during placing of grape clusters: (a) $480 \mathrm{~g}$; (b) $500 \mathrm{~g}$; (c) $530 \mathrm{~g}$.

\subsubsection{Behavior of Top and Bottom Berries during Placing}

Figure 11 shows the behavior of the top berry and the bottom berry during the placing of the grape cluster at an excitation speed of $1.0 \mathrm{~m} / \mathrm{s}$. The selected top berry is shown in red color; the bottom berry is in yellow. It can be seen from Figure 11 that at the start of the placing, there is no bending of the main rachis; hence, a small deflection of the berries at the top and bottom sides of the cluster was observed. When the cluster collided with the packaging material, the top berry deflected from the initial position due to the load coming from the bending of the main rachis; the bottom berry was also displaced from the initial position due to torsion between the pedicel and the berry. At the end of the placing phase, the top berry continued to deflect in some other direction. These continuous changes in the position of the berries decrease the connection strength between the berry and the pedicle and become the reason for berry drop in speedy robotic placings of grape clusters on both 
industrial and farm levels. These dropping of berries due to deflection during placing can be controlled by a force feedback mechanism.
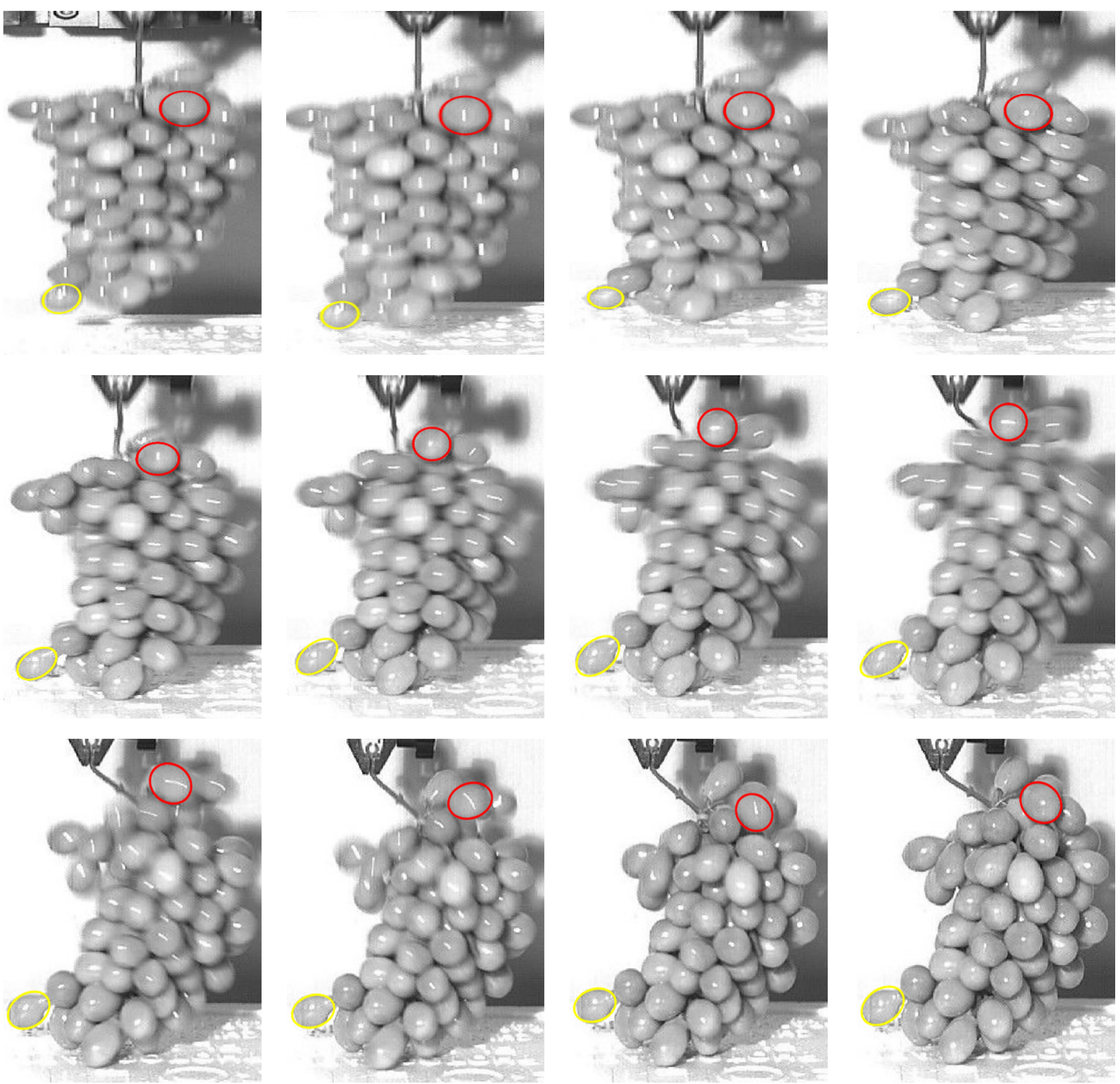

Figure 11. Behavior of berry deflection during robotic placing. Top berry in (red color) and bottom berry (yellow color).

\subsubsection{Relationship between the Cluster's Force before and after Impact}

It was observed from the experimental analysis that with the increase of speed, i.e., $(0.4,0.6,0.8$, and $1.0 \mathrm{~m} / \mathrm{s})$ of the actuator, the corresponding average magnitude of hanging force for all three grape cluster samples increased linearly (with $R^{2}=0.92,0.97,0.98$ ) at the start of the actuator's motion. Additionally, the magnitude of the force after impact with all three packaging surfaces decreased linearly (with $R^{2}=0.99,0.97,1$ ), as shown in Table 2 and Figure 12. This was due to the reason that the packaging surface bears the weight of the grape cluster during the stop of the actuator, which caused the berries' deflection from both the top and bottom sides of the cluster. It is easy to conclude that the higher the hanging force of the grape cluster, the greater the deflection of the cluster after striking the packaging surface, and more berry deflection occurs. There is a negative correlation between hang force and force after the impact of the cluster with a goodness 
of fit of $R^{2}=0.95$ at different speeds, as shown below in Figure 13. These results show that the cluster with high mass showed a high magnitude of hang force, but it strikes the packaging material with low deflection of the berries due to the compactness of the berries in the cluster with high mass.

Table 2. Hang and impact force under different speed intensities.

\begin{tabular}{ccccccc}
\hline $\begin{array}{c}\text { Speed } \\
(\mathbf{m} / \mathbf{s})\end{array}$ & $\begin{array}{c}\text { Hang Force } \\
\text { (Sample 1) } \\
\mathbf{( N )}\end{array}$ & $\begin{array}{c}\text { Hang Force } \\
\text { (Sample 2) } \\
\mathbf{( N )}\end{array}$ & $\begin{array}{c}\text { Hang Force } \\
\text { (Sample 3) } \\
\mathbf{( N )}\end{array}$ & $\begin{array}{c}\text { Impact with } \\
\text { Corrugated Box } \\
\mathbf{( N )}\end{array}$ & $\begin{array}{c}\text { Impact with } \\
\text { Expandable Polystyrene } \\
\text { Box (N) }\end{array}$ & $\begin{array}{c}\text { Impact with } \\
\text { Rigid Plastic Box } \\
(\mathbf{N})\end{array}$ \\
\hline 0.4 & 12.2 & 12.3 & 12.41 & 9.6 & 9.3 & 8.5 \\
0.6 & 12.25 & 12.35 & 12.49 & 9.5 & 9.25 & 8.4 \\
0.8 & 12.28 & 12.4 & 12.56 & 9.41 & 9.12 & 8.3 \\
1.0 & 12.4 & 12.42 & 12.6 & 9.28 & 9.05 & 1 \\
$R^{2}$ & 0.92 & 0.97 & 0.98 & 0.99 & 0.97 & 8.2 \\
\hline
\end{tabular}

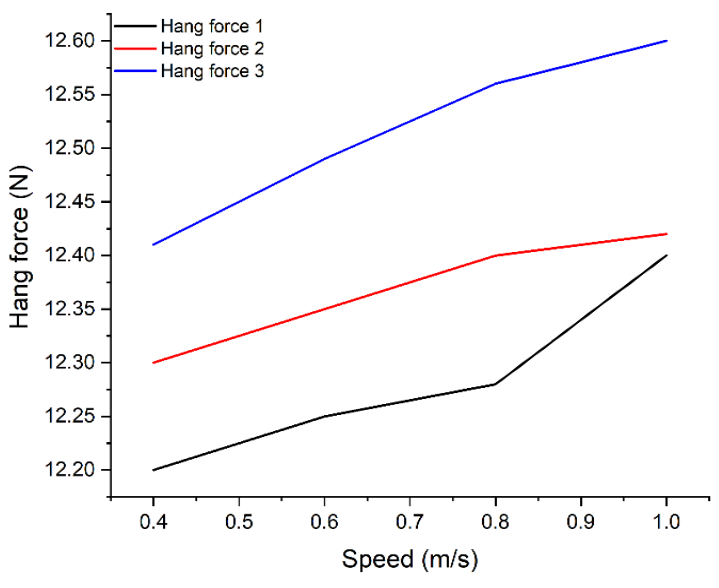

(a)

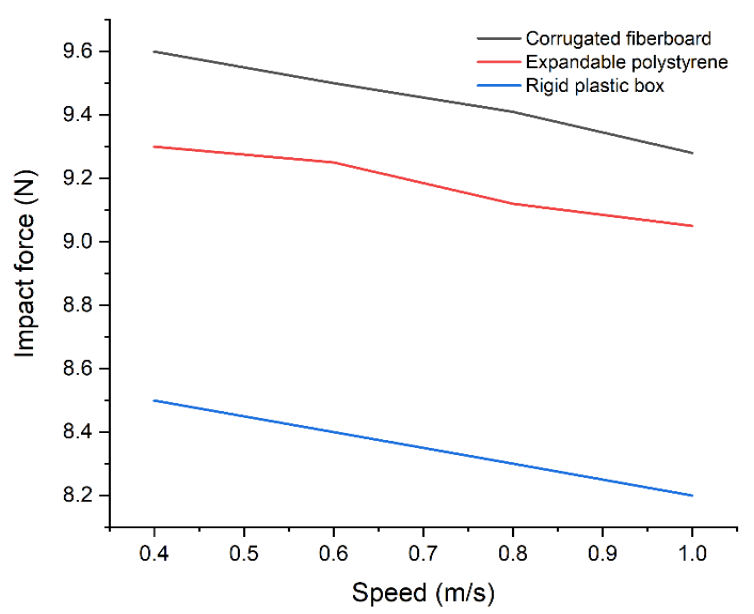

(b)

Figure 12. Effect of different speeds on the changes of forces during transportation and impact: (a) hanging force; (b) impact force.

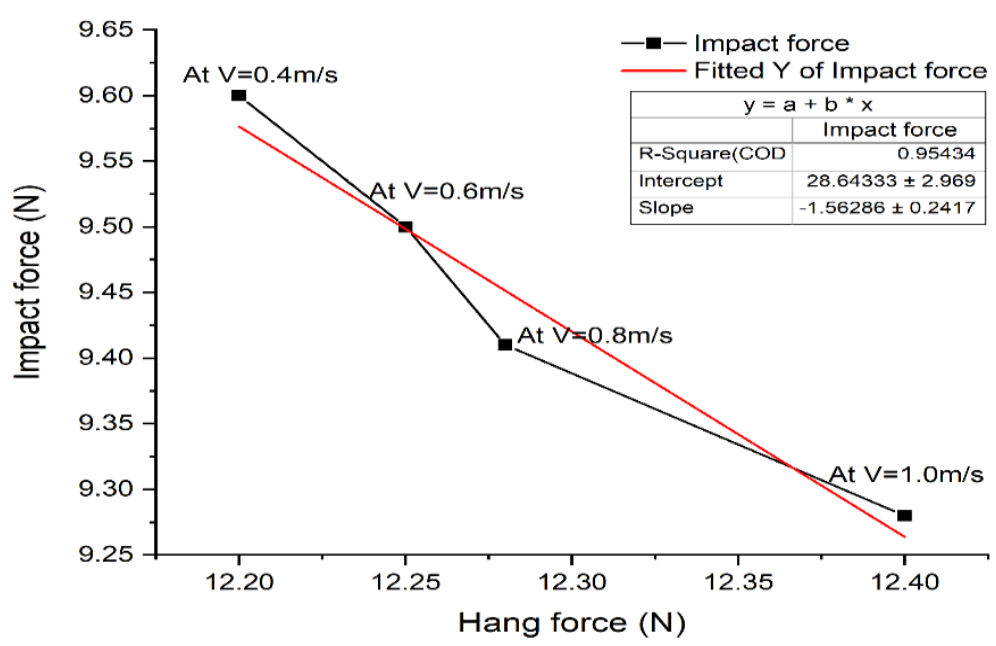

Figure 13. Relationship between hang force and impact force. 


\section{Conclusions}

In this paper, our aim was to observe the effect of different speed and acceleration excitations on the berry drop mechanism during the vertical transportation and placing of grape clusters. Force sensor signals and high-speed photography images were used for the verification of the deflection mechanism of the berries under different packaging materials. The following conclusions were drawn from this study:

1. It is concluded that the accelerating phase of the actuator causes high vibrations of the cluster during vertical transportation, and its magnitude increases with an increase in speed, so the hanging force signals also increase. The results of the peak force signals of the grape cluster during vertical transportation at different speeds $(0.4,1.0 \mathrm{~m} / \mathrm{s})$ suggest that the optimum acceleration excitation is $10 \mathrm{~m} / \mathrm{s}^{2}$, at which berry deflection is observed to be at a minimum.

2. It is concluded that with an increase in speed and acceleration excitation, the magnitude of force signals after colliding decreases due to the excitations coming from the packaging surface, which causes more berry deflection to occur.

3. It is concluded from the force sensor signals that rigid plastic boxes deflect the whole cluster most compared to expandable polystyrene and corrugated fiberboard boxes.

4. The behavior of the upper and lower berries was observed from the high-speed photography images during the placing of the whole cluster, and it is concluded that the deflection of the upper berries is due to the excitations coming from bending of the main rachis, and the deflection of lower berries is due to the torsional load on the junction between the pedicel and the berry.

5. It is observed from the vibration signals that with the increment in the mass of the cluster, the deflection of the berries decreases during placing.

Thus, research in this paper can act as a guide for the harvest and post-harvest robotic handling of cluster fruits such as grapes, cherries, blueberries, and litchi. The proposed study can be used to realize optimal control of the transportation and placing of the robot. Overall, this study provides technical and theoretical support for the industrial needs of low-loss robotic handling of different fresh-eating cluster fruits that are consumed abundantly. In the future, dynamic impact or collision between grape cluster berries during robotic post-harvest handling will be discussed.

Author Contributions: Conceptualization, J.L. and M.F.; methodology, M.F. and J.L.; software, M.F. and G.C.; validation, M.F., J.L., and G.C.; formal analysis, M.F. and J.L.; investigation, M.F., J.L., and I.A.; resources, M.F., J.L., and I.A.; data curation, J.L., M.F., and B.X.; writing-original draft preparation, M.F.; writing—review and editing, M.F., J.L., Z.S., and K.Y.; visualization, Z.S., and I.A.; supervision, J.L.; project administration, J.L.; funding acquisition, J.L. All authors have read and agreed to the published version of the manuscript.

Funding: The research was supported by grants from the National Science Foundation of China (Grant No. 31971795) and a project funded by the Priority Academic Program Development of Jiangsu Higher Education Institutions (No. PAPD-2018-87).

Institutional Review Board Statement: Not applicable.

Informed Consent Statement: Not applicable.

Data Availability Statement: Not applicable.

Acknowledgments: The authors are grateful to the National Science Foundation of China. The first author gives many thanks to the China Scholarship Council (2017GXZ026592) for providing 36 months of scholarship for studying in the People's Republic of China.

Conflicts of Interest: The authors declare no conflict of interest. 


\section{References}

1. FAO. FAOSTAT-Food and Agriculture Organization of the United Nations (FAO). Selection Criteria Grapes, All Countries, Prod. Quant. 2018. Available online: http/ / www.fao.org/faostat/en/\#data/QC2020 (accessed on 5 June 2021).

2. Jung, H.M.; Lee, S.; Lee, W.-H.; Cho, B.-K.; Lee, S.H. Effect of vibration stress on quality of packaged grapes during transportation. Eng. Agric. Environ. Food 2018, 11, 79-83. [CrossRef]

3. Rizzuti, A.; Aguilera-Sáez, L.M.; Gallo, V.; Cafagna, I.; Mastrorilli, P.; Latronico, M.; Pacifico, A.; Matarrese, A.M.S.; Ferrara, G. On the use of ethephon as abscising agent in cv. Crimson seedless table grape production: Combination of fruit detachment force, fruit drop and metabolomics. Food Chem. 2015, 171, 341-350. [CrossRef]

4. $\quad$ Deng, Y.; Wu, Y.; Li, Y.; Zhang, P.; Yang, M.; Shi, C.; Zheng, C.; Yu, S. A mathematical model for predicting grape berry drop during storage. J. Food Eng. 2007, 78, 500-511. [CrossRef]

5. Luo, L.; Tang, Y.; Zou, X.; Wang, C.; Zhang, P.; Feng, W. Robust grape cluster detection in a vineyard by combining the AdaBoost framework and multiple color components. Sensors 2016, 16, 2098. [CrossRef] [PubMed]

6. Liu, J.; Peng, Y.; Faheem, M. Experimental and theoretical analysis of fruit plucking patterns for robotic tomato harvesting. Comput. Electron. Agric. 2020, 173, 105330. [CrossRef]

7. Hussein, Z.; Fawole, O.; Opara, U.L. Harvest and postharvest factors affecting bruise damage of fresh fruits. Hortic. Plant J. 2020, 6, 1-13. [CrossRef]

8. Liu, J.; Yuan, Y.; Gao, Y.; Tang, S.; Li, Z. Virtual model of grip-and-cut picking for simulation of vibration and falling of grape clusters. Trans. ASABE 2019, 62, 603-614. [CrossRef]

9. Lichter, A.; Gabler, F.M.; Smilanick, J.L. Control of spoilage in table grapes. Stewart Postharvest Rev. 2006, 6, 1-10.

10. Chen, R.; Wu, P.; Cao, D.; Tian, H.; Chen, C.; Zhu, B. Edible coatings inhibit the postharvest berry abscission of table grapes caused by sulfur dioxide during storage. Postharvest Biol. Technol. 2019, 152, 1-8. [CrossRef]

11. Hussein, Z.; Fawole, O.; Opara, U.L. Preharvest factors influencing bruise damage of fresh fruits-A review. Sci. Hortic. 2018, 229, 45-58. [CrossRef]

12. $\mathrm{Hu}, \mathrm{X} . ; \mathrm{Xu}, \mathrm{Y} . ; \mathrm{Liu}, \mathrm{J}$. Design of vibration monitoring system and its application in grape fatigue damage research. In Proceedings of the 2nd International Conference on Control and Computer Vision, Jeju Island, Korea, 15-18 June 2019; pp. 141-149.

13. Jobbagy, J.; Kristof, K.; Schmidt, A.; Krizan, M.; Urbanovicova, O. Evaluation of the mechanized harvest of grapes with regards to harvest losses and economical aspects. Agron. Res. 2018, 16, 426-442.

14. Costa, W.V.D.; Elorza, P.B.; Garrido-Izard, M. Impact of local conditions and machine management on grape harvest quality. Sci. Agric. 2019, 76, 353-361. [CrossRef]

15. Fernando, I.; Fei, J.; Stanley, R.; Enshaei, H. Measurement and evaluation of the effect of vibration on fruits in transit-review. Packag. Technol. Sci. 2018, 31, 723-738. [CrossRef]

16. Gross, K.C.; Wang, C.Y.; Saltveit, M.E. Agriculture Handbook Number 66: The Commercial Storage of Fruits, Vegetables, and Florist and Nursery Stocks, 5th ed.; United States Department of Agriculture, Agriculture Research Service: Washington, DC, USA, 2016.

17. Mingjuan, L.; Xiangrong, Y.; Rende, W.; Yayuan, Z.; Jian, S.; Zhichun, L.; Changbao, L. Study on fruit quality and physiology and biochemistry of grapes during cold storage. South J. Agric. Sci. 2013, 44, 1883-1889.

18. Nicolosi, E.; Ferlito, F.; Amenta, M.; Russo, T.; Rapisarda, P. Changes in the quality and antioxidant components of minimally processed table grapes during storage. Sci. Hortic. 2018, 232, 175-183. [CrossRef]

19. Komarnicki, P.; Stopa, R.; Kuta, Ł.; Szyjewicz, D. Determination of apple bruise resistance based on the surface pressure and contact area measurements under impact loads. Comput. Electron. Agric. 2017, 142, 155-164. [CrossRef]

20. Stropek, Z.; Gołacki, K. Bruise susceptibility and energy dissipation analysis in pears under impact loading conditions. Postharvest Biol. Technol. 2020, 163, 111120. [CrossRef]

21. Hu, G.; Chen, J. Transverse anisotropy mechanical properties and drop test of apple. In Proceedings of the 2020 ASABE Annual International Virtual Meeting, Omaha, NE, USA, 13-15 July 2020; p. 1.

22. Yousefi, S.; Farsi, H.; Kheiralipour, K. Drop test of pear fruit: Experimental measurement and finite element modelling. Biosyst. Eng. 2016, 147, 17-25. [CrossRef]

23. Shafie, M.M.; Rajabipour, A.; Mobli, H. Determination of bruise incidence of pomegranate fruit under drop case. Int. J. Fruit Sci. 2017, 17, 296-309. [CrossRef]

24. Opara, L.U.; Al-Ghafri, A.; Agzoun, H.; Al-Issai, J.; Al-Jabri, F.; Opara, U.L. Design and development of a new device for measuring susceptibility to impact damage of fresh produce. N. Z. J. Crop. Hortic. Sci. 2007, 35, 245-251. [CrossRef]

25. Wang, W.; Zhang, S.; Fu, H.; Lu, H.; Yang, Z. Evaluation of litchi impact damage degree and damage susceptibility. Comput. Electron. Agric. 2020, 173, 105409. [CrossRef]

26. Van Zeebroeck, M.; Tijskens, E.; Liedekerke, P.; Deli, V.; Baerdemaeker, J.; Ramon, H. Determination of the dynamical behaviour of biological materials during impact using a pendulum device. J. Sound Vib. 2003, 266, 465-480. [CrossRef]

27. Stropek, Z.; Gołacki, K. Impact characteristics of pears. Postharvest Biol. Technol. 2019, 147, 100-106. [CrossRef]

28. Öztekin, Y.B.; Güngör, B. Determining impact bruising thresholds of peaches using electronic fruit. Sci. Hortic. 2019, 262, 109046. [CrossRef]

29. Praeger, U.; Surdilovic, J.; Truppel, I.; Herold, B.; Geyer, M. Comparison of electronic fruits for impact detection on a laboratory scale. Sensors 2013, 13, 7140-7155. [CrossRef] [PubMed] 
30. Surdilovic, J.; Praeger, U.; Herold, B.; Truppel, I.; Geyer, M. Impact characterization of agricultural products by fall trajectory simulation and measurement. Comput. Electron. Agric. 2018, 151, 460-468. [CrossRef]

31. Stropek, Z.; Gołacki, K. Quantity assessment of plastic deformation energy under impact loading conditions of selected apple cultivars. Postharvest Biol. Technol. 2016, 115, 9-17. [CrossRef]

32. Horabik, J.; Beczek, M.; Mazur, R.; Parafiniuk, P.; Ryżak, M.; Molenda, M. Determination of the restitution coefficient of seeds and coefficients of visco-elastic Hertz contact models for DEM simulations. Biosyst. Eng. 2017, 161, 106-119. [CrossRef]

33. Liang, N.; Ni, F.; Zhang, K.; Tang, Y.; Hu, Y. Optimized installation angle and distance of a grading channel for dried jujube fruit with a push-pull actuating mechanism. Comput. Electron. Agric. 2018, 150, 134-142. [CrossRef]

34. Jinwu, W.; Han, T.; Jinfeng, W.; Dongxuan, J.; Xin, L. Measurement and analysis of restitution coefficient between maize seed and soil based on high-speed photography. Int. J. Agric. Biol. Eng. 2017, 10, 102-114.

35. Xia, M.; Zhao, X.; Wei, X.; Guan, W.; Wei, X.; Xu, C.; Mao, L. Impact of packaging materials on bruise damage in kiwifruit during free drop test. Acta Physiol. Plant. 2020, 42, 1-11. [CrossRef]

36. Zhou, J.; He, L.; Karkee, M.; Zhang, Q. Effect of catching surface and tilt angle on bruise damage of sweet cherry due to mechanical impact. Comput. Electron. Agric. 2016, 121, 282-289. [CrossRef]

37. Du, D.; Wang, B.; Wang, J.; Yao, F.; Hong, X. Prediction of bruise susceptibility of harvested kiwifruit (Actinidia chinensis) using finite element method. Postharvest Biol. Technol. 2019, 152, 36-44. [CrossRef]

38. Fu, H.; He, L.; Ma, S.; Karkee, M.; Chen, D.; Zhang, Q.; Wang, S. 'Jazz' apple impact bruise responses to different cushioning materials. Trans. ASABE 2017, 60, 327-336. [CrossRef]

39. Deng, W.; Wang, C.; Xie, S. Impact peak force measurement of potato. Int. J. Food Prop. 2020, 23, 616-626. [CrossRef]

40. Hussein, Z.; Fawole, O.A.; Opara, U.L. Bruise damage susceptibility of pomegranates (Punica granatum, L.) and impact on fruit physiological response during short term storage. Sci. Hortic. 2019, 246, 664-674. [CrossRef]

41. Vinokur, Y.; Rodov, V.; Levi, A.; Kaplunov, T.; Zutahy, Y.; Lichter, A. A method for evaluating fruit abscission potential of grapes and cherry tomato clusters. Postharvest Biol. Technol. 2013, 79, 20-23. [CrossRef]

42. Mohsenin, N.N. Physical Properties of Plant and Animal Materials; Routledge: Abingdon, UK, 1986.

43. Kupferman, E. Minimizing Bruising in Apples; Postharvest Information Network, Washington State University, Tree Fruit Research and Extension Center: Wenatchee, WA, USA, 2006.

44. Fahe, C.; Xin, Y.; Weiyi, Z. Study on relationship between pedicel structure and berry abscission of 'Xinjiang wuhebai' grape cultivars. J. Xinjiang Agric. Univ. 2000, 1, 44-48.

45. Youmei, W.; Xuezeng, H.; Yu, L.; Jianchuan, R. Postharvest berry abscission and storage of grape fruit. Acta Phytophysiol. Sin. 1992, 18, 267-272.

46. Zahedipour, P.; Asghari, M.; Abdollahi, B.; Alizadeh, M.; Danesh, Y.R. A comparative study on quality attributes and physiological responses of organic and conventionally grown table grapes during cold storage. Sci. Hortic. 2019, 247, 86-95. [CrossRef]

47. Zhang, Z.; Xu, J.; Chen, Y.; Wei, J.; Wu, B. Nitric oxide treatment maintains postharvest quality of table grapes by mitigation of oxidative damage. Postharvest Biol. Technol. 2019, 152, 9-18. [CrossRef]

48. Vázquez-Hernández, M.; Navarro, S.; Sanchez-Ballesta, M.T.; Merodio, C.; Escribano, M.I. Short-term high $\mathrm{CO}_{2}$ treatment reduces water loss and decay by modulating defense proteins and organic osmolytes in Cardinal table grape after cold storage and shelf-life. Sci. Hortic. 2018, 234, 27-35. [CrossRef]

49. Liguori, G.; Sortino, G.; Gullo, G.; Inglese, P. Effects of modified atmosphere packaging and chitosan treatment on quality and sensorial parameters of minimally processed cv. 'Italia' table grapes. Agronomy 2021, 11, 328. [CrossRef]

50. Pezzi, F.; Caprara, C.; Bordini, F. Transmission of impacts during mechanical grape harvesting and transportation. J. Agric. Eng. 2008, 39, 43-48. [CrossRef]

51. Caprara, C.; Pezzi, F. Measuring the stresses transmitted during mechanical grape harvesting. Biosyst. Eng. 2011, 110, 97-105. [CrossRef]

52. Yue, X.; Wu, P.; Wang, S.; Liu, Y.; Su, H. Experimental analysis of drop and vibration damage during grape storage and transportation. Packag. Eng. 2019, 40, 9-18.

53. Bian, H.; Tu, P. The influence of drop height on the dielectric properties of Red Globe grapes. Food Ferment. Ind. 2013, 39, 154-157.

54. Vallone, M.; Alleri, M.; Bono, F.; Catania, P. Acceleration assessment during mechanical harvest of grapes using a non commercial instrumented sphere. Chem. Eng. Trans. 2017, 58, 277-282.

55. Fischer, D.F.; Craig, W.L.; Ashby, B.H. Reducing transportation damage to grapes and strawberries. J. Food Distrib. Res. 1990, 21, 193-202.

56. Fischer, D.; Craig, W.L.; Watada, A.E.; Douglas, W.; Ashby, B.H. Simulated in-transit vibration damage to packaged fresh market grapes and strawberries. Appl. Eng. Agric. 1992, 8, 363-366. [CrossRef]

57. Lixin, L. Dynamic mechanical model of fruit under drop impact. Eng. Mech. 2009, 4, 228-233.

58. Hao, D. Research on the Key Factors Affecting the Quality of Kyoho Grapes during Storage and Transportation. Master's Thesis, Tianjin University of Commerce, Tianjin, China, 2016.

59. Demir, F.; Kara, Z.; Carman, K. Table grapes transport simulation study by Bardas (Vitis vinifera L.) cultivar grown in Karaman Turkey. In Proceedings of the 2nd International Symposium on Sustainable Development, Sarajevo, Bosnia and Herzegovina, 8 June 2010; pp. 456-463. 
60. Kondo, N.; Tanihara, K.; Shiigi, T.; Shimizu, H.; Kurita, M.; Tsutsumi, M.; Chong, V.K.; Taniwaki, S. Path planning of tomato cluster harvesting robot for realizing low vibration and speedy transportation. Eng. Agric. Environ. Food 2009, 2, 108-115. [CrossRef]

61. Liu, J.; Tang, S.; Shan, S.; Ju, J. Simulation and test of grape fruit cluster vibration for robotic harvesting. Trans. Chin. Soc. Agric. Mach. 2016, 47, 1-8.

62. Faheem, M.; Liu, J.; Chang, G.; Ahmad, I.; Peng, Y. Hanging force analysis for realizing low vibration of grape clusters during speedy robotic post-harvest handling. Int. J. Agric. Biol. Eng. 2021, 14, 62-71. [CrossRef]

63. Peacock, B.; Simpson, T. The Relationship between Berry Weight, Length and Width for Five Table Grape Varieties; University of California Cooperative Extension (UCCE): Tulare County, CA, USA, 2017; Publ. TB1-95.

64. Mack, J.; Rist, F.; Herzog, K.; Töpfer, R.; Steinhage, V. Constraint-based automated reconstruction of grape bunches from 3D range data for high-throughput phenotyping. Biosyst. Eng. 2020, 197, 285-305. [CrossRef]

65. Wang, Z.; Zhang, Y.; Wang, Q.; Dong, K.; Yang, S.; Jiang, Y.; Zheng, J.; Li, B.; Huo, Y.; Wang, X.; et al. Dynamics of droplet formation with oscillation of meniscus in electric periodic dripping regime. Exp. Therm. Fluid Sci. 2021, 120, 110250. [CrossRef]

66. Rekhviashvili, S.; Pskhu, A.; Agarwal, P.; Jain, S. Application of the fractional oscillator model to describe damped vibrations. Turk. J. Phys. 2019, 43, 236-242. [CrossRef] 